\title{
Unusual branches of facial artery and their clinical significance
}

\author{
Mohd.Saleem Itoo ${ }^{*}$, Shamima Banoo ${ }^{2}$, Shaheen Shahdad ${ }^{3}$, Javeed Khan ${ }^{2}$, Fahmida Akhter ${ }^{4}$ \\ Pandith Tafiq John ${ }^{4}$, Omer Bashir Itoo ${ }^{4}$, Shafaq Masood ${ }^{4}$ \\ ${ }^{1}$ Assistant Professor Department of Anatomy Government Medical College Srinagar, J\&K, India \\ ${ }^{2}$ Lecturer Department of Anatomy Government Medical College Srinagar, J\&K, India \\ ${ }^{3}$ Professor Department of Anatomy Government Medical College Srinagar, J\&K, India \\ ${ }^{4}$ Assistant Surgeon Department of Anatomy/Medicine Government Medical College Srinagar, J\&K, India \\ *Corresponding author E-mail: dr.saleem68@gmail.com
}

\begin{abstract}
The Present study was conducted in the Department of Anatomy Government Medical College Srinagar to observe the variations in the branching pattern of facial artery. The aim of this study was to make clinicians academically wiser and practically more competent while dealing with these anomalous branches during surgery and other interventional procedures. Bilateral head and neck dissection of a formalin preserved middle aged Indian male cadaver was done for routine teaching and simultaneously observations regarding the branching pattern of facial artery were recorded. It was observed that left facial artery gave an anomalous branch mid-way between the masseter and inferior labial artery. This anomalous branching pattern of facial artery though rare is of great academic and clinical significance in general practice, Otorhinology, Traumatology, Plastic and Maxillofacial surgery. These anomalies should be kept in mind and given due honour while operating and intervening in the region of face for emergency management of injuries, correction of congenital anomalies and while performing other general and specialized surgical procedures in this region.
\end{abstract}

\section{Introduction}

The main arterial supply to the face is derived from the facial and superficial temporal arteries. Blood is also supplied by branches of the maxillary and ophthalmic arteries. Facial artery arises in the neck from the external carotid artery. This is the third anterior branch of external carotid artery. It arises immediately above the origin of lingual artery and ends at the medial angle of the eye after a tortuous course. It lies deep to the posterior belly of digastric and stylohyoid muscle separated from palatine tonsil only by the superior constrictor muscle. Just above stylohyoid it enters a groove in sub mandibular gland [1] and runs downwards between the lateral surface of the gland and medial pterygoid muscle to the lower border of the mandible. Turning round this border of the bone it enters the face at the anterioinferior border of masseter where its pulsations can be felt. Thence it passes sinuously towards the angle of mouth, giving off labial branches 1.0 to $1.5 \mathrm{~cm}$ from the angle of mouth and ascends more vertically to the medial angle of the eye (angular artery). It passes onto the face at the anterioinferior border of masseter where its pulse can be felt as it crosses the mandible. It is superficial and at first and lies beneath the Platysma. It is covered by skin, the fat of the cheek and near the angle of mouth by Zygomaticus major and risorius. It pursues a tortuous course that presumably allows it to stretch when the face is distorted during jaw opening by the side of the nose towards the medial corner of the mouth. Occasionally, the facial artery barely extends beyond the angle of the mouth, in which case its normal territory beyond this region is taken over by an enlarged transverse facial branch from the superficial temporal artery and the branches from contralateral facial artery [2]. The facial artery being the chief artery of the face [3] supplies branches to the adjacent muscles and the skin of the face. The facial artery may be tortuous or fairly straight, but in any event the course of facial vessels is an oblique one past the corner of the mouth and alongside of the nose. Its named branches on the face are premassetric artery, the inferior and superior labial arteries and the lateral nasal artery. The sub mental artery arises from the facial artery at the lower border of the body of mandible. It supplies the skin of the chin and lower lip [4] and the part of the artery distal to its terminal branch is called angular artery.

Premassetric artery is a small inconsistent branch [2], it passes upwards along the anterior border of masseter and supplies the adjacent tissue. Before the artery reaches the corner of the lip, it gives off inferior labial artery that runs 
medially in the lower lip and anastomoses with its fellow of the opposite side, this artery may be double [3]. It next gives off superior labial artery to the upper lip. The superior labial artery being larger and more tortuous than inferior labial artery. It anastomoses with its fellow of the opposite side and supplies the upper lip. It gives off a septal branch (coronary artery of the nose) which ramifies anterioinferiorly in the nasal septum and also gives an alar branch. This septal branch anastomoses with septal branches of nasopalatine and anterior ethmoidal arteries. Thereafter, it runs along the side of the nose towards the medial angle of the eye as the angular artery. Instead of ending up by breaking into small branches, the angular artery may anastomose with a terminal branch of ophthalmic artery (dorsalis nasi) that leaves the orbit and runs downwards to supply the nose. Lateral nasal artery is given off by the side of nose. Sometimes the angular artery is very poorly developed or absent [2]. It supplies dorsum and alae of the nose and anastomoses with its fellow of the opposite side. It may be replaced by a branch of the superior labial artery. The facial artery also anastomoses with transverse facial artery (from superficial temporal artery). Thus there is a very extensive network of anastomoses between the terminal branches of external and internal carotid artery of one side with their counterparts of the other side. This is the reason why wounds of face bleed profusely, heal quickly and need manipulation of vessels on both sides of the face to stop bleeding. The submental artery arises from the facial artery at the lower border of the body of mandible. It supplies the skin of the chin and lower lip [5].There are numerous communications between the branches of facial artery and other arteries of the face, hence compressing the facial artery against the mandible on one side does not stop all bleeding. Because the branches of the external carotid artery anastomose so freely with each other and with those of external carotid artery on the other side, one external carotid artery can be clamped in order to minimize bleeding and thus facilitate extensive surgery on one side of the face.

\section{Materials and methods}

The present study was carried out in the Department of Anatomy Government Medical College Srinagar, Kashmir, India during routine dissection of a formalin preserved middle aged Indian male cadaver for undergraduate Anatomic teaching and recording observations. Bilateral dissection of head and neck was done was done carefully and strictly following instructions given in the Cunningham's manual of practical Anatomy and observed for variations in the branching pattern of facial artery. Appropriate photographs were taken and labelled as shown in figure, [1].

\section{Case report}

During routine dissection of a middle aged Indian male cadaver in the Department of Anatomy Government Medical College Srinagar, we observed that left facial artery originated from external carotid artery just above the lingual artery as usual. After crossing the anterioinferior border of masseter, it gave a medium sized anomalous and unnamed branch midway between the anteriorinferior border of masseter muscle and the origin of inferior labial artery. This anomalous branch passes upwards and medially towards the infraorbital margin and divides into three small terminal branches which anastomose with the terminal branches of infraorbital and transverse facial arteries as shown in the fig, [1]. The superior labial, lateral nasal and angular branches present on the left side were relatively of smaller size than their counterparts on the right side. The premassetric branch was not present on either side of the face in this cadaver. On the right side facial artery gave the usual branches namely inferior labial, superior labial, lateral nasal and the angular artery.

\section{Discussion}

There are available reports in the literature related to the variable origin, course and the branching pattern of facial artery in face. Facial artery is the anterior branch of external carotid artery, given off in the carotid triangle [6]. The course of facial artery is divided into two parts, the cervical and the facial. The facial artery is tortuous throughout its extent. The cervical part is tortuous to adapt to the movements of pharynx during deglutition. The facial part is tortuous to adapt to the movements of mandible, lips and cheek. The facial artery is felt on the base of mandible at the anterioinferior border of masseter. The anesthetists often feel the facial pulse for monitoring the patient during surgery that is why it is called anesthetists artery [6]. The usual branches of facial artery in the face are inferior labial, superior labial, lateral nasal and angular artery. The premassetric branch [2] also finds its limited description in the available literature. The facial artery and lingual artery may arise by a common stem [7] called linguofacial trunk. Anne M. R. Agur (1991) [7] studied variations in origin of facial artery in 211 specimens. In $80 \%$ of specimens the superior thyroid, 
lingual and facial arteries arose separately. In $20 \%$ of cases lingual and facial arteries arose from a common stem. In one specimen, the superior thyroid and lingual arteries arose by a common stem. Marx C etal (2008) [8] reported a case where facial artery showed bilateral variation in origin and branching pattern. In a 65 year old male cadaver they found that right facial artery taking origin from external carotid artery did not make a loop in the sub mandibular region, entered the face by winding round the lower border of mandible and terminated as inferior labial artery. The upper part of the right side of face in this case was supplied by the branches of transverse facial artery, infra orbital artery and dorsal nasal artery. The origin course and branching pattern of left facial artery in this case was normal except that inferior labial artery was missing from it. In our present study we found that left facial artery gives an anomalous branch proximal to the origin of inferior labial artery. This medium sized and unnamed branch divided into three terminal branches which proceeded towards the infra orbital margin and anastomosed with the terminal branches of infra orbital and transverse facial artery. The superior labial, lateral nasal and angular arteries were of smaller dimensions as compared to their counterparts on the right side. The left inferior labial artery in this case was larger than the right inferior labial artery. The smaller size of left superior labial, lateral nasal and angular arteries is compensated by the anomalous medium sized artery and its terminal branches which anastomose with the surrounding vessels. The knowledge about this anomalous branching pattern of facial artery is very essential for general practitioners and traumatologists who receive profusely bleeding facial injuries for first aid and specialized management respectively. Maxillofacial and plastic surgeons should also give due honour to these anomalies before deciding about grafts and other surgical interventions in this region. Thus it is very important for general surgical practitioners and specialists to know about this anomalous branching pattern of facial artery for efficient management of injuries, correction of congenital anomalies like cleft lip,cleft palate and while dealing with other pathologies of maxillofacial region.

\section{Summary and conclusion}

The main arterial supply of face comes from facial artery. The variations in the branching pattern of this important vessel though rare, are of immense academic and clinical significance in general practice, Traumatology, Maxillofacial and Plastic Surgery. This rare anomalous branch of left facial artery reported by us does not find its description in the available literature. It should be kept in mind and given due recognition and respect in academics and general surgical practice. During specialized and super specialized surgical interventions of facial artery a sound knowledge of this variation can change the surgical outcome and external appearance of a patient.

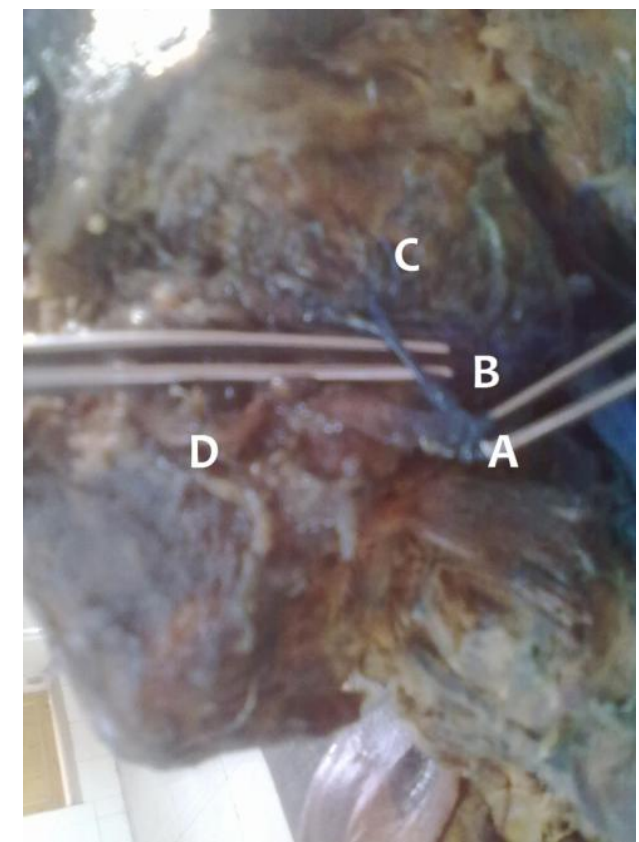

A. Facial artery

B. Unusual branch from facial artery

C. Three branches from unusual artery

D. Inferior labial artery

Fig.1: Showing an unusual branch of facial artery originating between masseter and inferior labial artery and dididing into three terminal branches.

\section{References}

[1] G.R. ROMANES,Cunningham's Textbook of Anatomy, Twelfth edition,OXFORD UNIVERSITY PRESS,Oxford New York Toronto $1981 ; 902$ 
[2] Standring S.Gray's Anatomy-The anatomical basis of clinical practice.39th edition Edinburg Elsevier Churchill Livingstone; 2005, 509-510.

[3] Hollinshed's Textbook of Anatomy,fifth Edition. Lppincott-Raven.publishers; Philadelphia. NewYork 1997; 755

[4] Keith L. MOORE,Clinically oriented ANATOMY,WILLIAMS \&WILLKINS,Balmatore/London ,1980;890-891

[5] RICHARD S. SNELL, Clinical Anatomy.LIPPINCOTT WILLIAM'S WILKINS, 7th edition, $2004 ; 768$.

[6] Neeta V Kulkarni,CLINICAL ANATOMY (A Problem Solving approach) ,Japee brothers, New delhi, second edition,2012326-328.

[7] Anne M. R. Agur, Grants ATLAS OF ANATOMY,Williams \& Wilkins,London,Ninth edition 1991, 562-63.

[8] Marx C etal,Bilateral variations of facial artery,a case report, Rom J morphol Embryol 2008,49(3);399-401. 